\title{
Exposure to environmental tobacco smoke and risk of lung cancer: the epidemiological evidence
}

\section{To the Editor:}

In their review article, TRÉDANIEL et al. [1] consider the causal association between environmental tobacco smoke exposure and lung cancer to be an established fact, even if the well-known criteria for causality are only partly met. The question arises, whether there are possible alternative explanations for this association.

The authors, as well as others, admit that misclassification of current or ex-smokers as lifetime nonsmokers may falsely increase the lung cancer risk associated with passive smoking. They are right in distinguishing between current smokers, of whom 1-6\% (mean value $2.5 \%$ ) deny their habit [2], and ex-smokers, who, after giving up smoking, claim that they have never smoked. The full, and certainly unexpected, extent of the former smoking habit has become apparent in the World Health Organization (WHO) Augsburg MONICA Study [3]. Of 2,840 study volunteers interviewed in 1983-1984, 688 reported that they were ex-smokers. Four years later, 121 (i.e. 17.6\%) of them claimed never to have smoked. We can only guess how high their proportion will be in $20 \mathrm{yrs}$, when the latency period for lung cancer is gradually ending. Since the lung cancer risk of ex-smokers only decreases slowly and probably never returns to the level of lifetime nonsmokers, it is of course totally inappropriate to include ex-smokers in the case group, as has been done in one of the largest studies [4] reviewed by the authors. In view of these findings, we have to be concerned that the slightly elevated lung cancer risk of passive smokers might be attributable to misclassification to a greater degree than has hitherto been assumed.

The authors further agree that confounding variables, if not properly standardized for in the data analysis, may cause an increase in lung cancer risk that is falsely associated with passive smoking [5-10]. It is well-known, that families of smokers are found predominantly in poorer social classes and in urban areas; they tend to drink more alcohol and eat more fat and less vitamins. Nonsmokers married to smokers usually adopt the lifestyle and, particularly, the eating habits of their smoking partners. The differences are so significant that they inevitably affect the lung cancer risk of the patient group in casecontrol studies, quite irrespective of passive smoking. For example, Alavanja et al. [11] have shown, in their study on lung cancer risk of nonsmokers, that in the group with the highest fat consumption the incidence of adenocarcinomas was 11 times higher than in the group with the lowest fat consumption. This finding is of particular significance, since this type of cancer has primarily been associated with passive smoking, particularly in the most important studies [4, 12, 13].

What has hardly been considered by the authors is the fact that even in these studies the patient groups differ from the control groups in many more variables than simply tobacco smoke exposure [4, 12, 13]. It is wellknown that members of poorer social classes only rarely volunteer as controls for such studies. If, as in these studies, selection for the control group presupposes that a telephone can be used for the interview, a selection bias is reinforced even further. In addition, the response rate in the control group is usually lower than in the case group, which probably explains why it is not mentioned at all in one of these studies [12]. In view of the many methodological limitations, it is not surprising that subjects with poor education and a lower income are found predominantly in the patient group. Moreover, if, as in these studies, different methods are used to interview the cases and the controls, the results might inevitably be biased by systemic errors.

In the USA, smoking-related mortality rates for persons with an education below high school level have been found to be three times higher than for college graduates [14]. This certainly includes deaths from lung cancer, since this association has been established for the UK [15]. The reason for this is still unknown. However, if in clinical studies the direct effect of the factor to be examined, e.g. passive smoking, has been found to be quite small as compared to the confounder, e.g. the socio-economic status, it is almost impossible that the effects caused by the confounder are standardized for using statistical methods [15]. By stratifying the study population by education and/or income, at least some of the investigators have shown that they are well aware of the problem [12, 13], but they are certainly unable to solve it in this way.

The large number of methodological inadequacies in the studies available support the view that the lung cancer risk due to passive smoking is more likely to be a biostatistical artefact than a reliable measure which could confirm a causal relationship. This view is in line with the opinion of prominent epidemiologists [16-18].

\section{F. Adlkofer, W-D. Heller}

Analytisch-biologisches Forschungslabor, Goethestrasse 20, D-80336 München, Germany.

\section{References}

1. Trédaniel J, Boffetta P, Saracci R, Hirsch A. Environmental tobacco smoke and lung cancer risk: the epidemiological evidence. Eur Respir J 1994; 7: 1877-1888. 
2. Lee PN. Misclassification of Smoking Habits and Passive Smoking. A Review of the Evidence. Berlin, SpringerVerlag, 1988.

3. Heller W-D, Sennewald E, Gostomzyk J-G, Scherer G, Adlkofer F. Validation of ETS exposure in a representative population in Southern Germany. In: Jantunen M, Kalliokoski P, Kukkonen E, Saarela K, Seppänen O, Vuorelma H, eds. Indoor Air 1993. Vol. 3. Combustion Products, Risk Assessment, Policies. Proceedings of the 6th International Conference on Indoor Air Quality and Climate. Helsinki; Indoor Air 1993, 1993; pp. 361365.

4. Brownson RC, Alavanja MCR, Hock ET, Loy TS. Passive smoking and lung cancer in nonsmoking women. Am J Public Health 1992; 82: 1525-1530.

5. Rylander R. Environmental tobacco smoke and lung cancer. N Engl J Med 1990; 323: 834.

6. Butler WJ. Cancer of the lung and larynx. Am J Epidemiol 1991; 134: 724.

7. Van Poppel G, Kok FJ, Gorgels WJMJ, Schrijver J. Lung cancer and exposure to tobacco smoke in the household. $N$ Engl J Med 1991; 324: 413-414.

8. Margetts BM, Jackson AA. Interactions between people's diet and their smoking habits: the dietary and nutritional survey of British adults. Br Med J 1993; 307: 1381-1384.

9. Matanoski GM, Kanchanaraksa S. Characteristics of nonsmoking women in NHANES I with exposure to smoking spouses. Submitted to OSHA, Federal Register, Vol. 59, No. 65, Docket no. H-122, 1994.
10. Thornton A, Lee P, Fry F. Differences between smokers, ex-smokers, passive smokers and nonsmokers. $J$ Clin Epidemiol 1994; 47: 1143-1162.

11. Alavanja MCR, Brown CC, Swanson C, Brownson RC. Saturated fat intake and lung cancer risk among nonsmoking women in Missouri. J Natl Cancer Inst 1993; 85: 1906-1915.

12. Stockwell HG, Goldman AL, Lyman GH, et al. Environmental tobacco smoke and lung cancer risk in nonsmoking women. J Natl Cancer Inst 1992; 84: 1417-1422.

13. Fontham ETH, Correa P, Reynolds P, et al. Environmental tobacco smoke and lung cancer in nonsmoking women: a multicenter study. J Am Med Assoc 1994; 271: 17521759.

14. Angell M. Privilege and health: What is the connection? N Engl J Med 1993; 329: 126-127.

15. Marmot MG, Shipley MJ, Rose G. Inequalities in death: Specific explanations of a general pattern? Lancet 1984; 323: 1003-1006.

16. Wynder EL, Hoffmann D. Smoking and lung cancer: scientific challenges and opportunities. Cancer Res 1984; 54: 5284-5295.

17. Fleiss JL, Gross AJ. Meta-analysis in epidemiology, with special reference to studies of the association between exposure to environmental tobacco smoke and lung cancer: a critique. J Clin Epidemiol 1991; 44: 127-139.

18. Feinstein AR. Quality of science and statistics in ETS studies. In: The Toxicology Forum. Proceedings of the 1993 Annual Summer Meeting, Aspen. Washington: The Toxicology Forum, 1993; pp. 330-340.

\section{REPLY}

\section{From the authors:}

In their letter, Adlkofer and Heller discuss three main points, namely misclassification of smoking status, existence of confounding variables, especially diet, and selection bias of controls. Excluding this last point, which is not clearly documented in the literature, misclassification and confounding have already been extensively discussed; we examined these problems in our review [1].

We agree with these authors that such problems still have to be discussed for each new study when published. Indeed, the critical reviewer can find shortcomings in most of the published studies of environmental tobacco smoke (ETS) and lung cancer. However, given our current knowledge of the chemical constituents both of sidestream and mainstream tobacco smoke, of the materials absorbed during passive smoking, and of the quantitative relations between dose and effect that are commonly observed in exposure to carcinogens, it is generally admitted that

exposure to ETS causes some increase in the risk of lung cancer [2]. At this point of the story, we think that it is up to the contradictors to provide convincing and conclusive evidence that passive smoking is not associated with elevated risk of lung cancer. In the absence of such evidence, we have to accept that exposure to ETS is carcinogenic to humans [3].

\section{J. Trédaniel, P. Boffetta, R. Saracci, A. Hirsch}

Service de Pneumologie, Hôpital Saint-Louis, 1, Avenue Claude Vellefaux, 75475 Paris Cedex 10, France.

\section{References}

1. Trédaniel J, Boffetta P, Saracci R, Hirsch A. Environmental tobacco smoke and lung cancer risk; the epidemiological evidence. Eur Respir J 1994; 7: 1877-1888.

2. Boyle P. The hazards of passive - and active - smoking. N Engl J Med 1993; 328: 1708-1709.

3. La Vecchia C. A Popperian approach to the passive smoking issue. Int J Cancer 1992; 51: 159. 